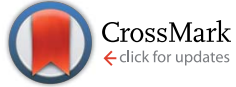

Cite this: RSC Adv., 2015, 5, 14958

Received 15th November 2014 Accepted 23rd January 2015

DOI: $10.1039 / c 4 r a 14619 k$

www.rsc.org/advances

\section{Synthesis of multiarm star copolymers based on polyglycerol cores with polylactide arms and their application as nanocarriers $\uparrow$}

\begin{abstract}
M. Adeli, ${ }^{\text {ab }}$ H. Namazi, ${ }^{\text {c }}$ F. Du, ${ }^{\text {a }}$ S. Hönzke, ${ }^{d}$ S. Hedtrich, ${ }^{d}$ J. Keilitz ${ }^{a}$ and R. Haag ${ }^{\star a}$
Hyperbranched polyglycerol (hPG) with two different molecular weights ( $\mathrm{hPG} 2400$ and $\mathrm{hPG} 8000$ ) was used as a macroinitiator for the polymerization of lactide. Thereby, amphiphilic linear-dendritic multiarm star copolymers (MSCs) were prepared and investigated with regard to their ability to encapsulate and transport guest molecules. Various ratios of monomer to hydroxy functional end groups ([LA]/[OH]) were used for the preparation of linear-dendritic multiarm copolymers with different degrees of polymerization (DP), molecular weight, and arm multiplicity. At high molecular weights almost all of the hydroxy groups of hPG were reacted with the lactide monomer and the number of arms was equal to the number of hydroxy functional groups. The ability of the synthesized MSCs to encapsulate and transport small guest molecules was examined. The transport capacity (TC) of all nanocarriers under different conditions was investigated using the model dye Congo red as well as the model drug 5-aminosalicylic acid (5-ASA). With both $\mathrm{hPG}_{2400}$ and $\mathrm{hPG}_{8000}$ cores, the TC increased along with an increasing number and length of the arms. The dependence of the TC on the concentration of MSCS was also investigated and found to deteriorate with increasing polymer concentration. Finally the ability of the synthesized nanocarriers to penetrate into the skin and transport Nile red through this barrier was successfully investigated.
\end{abstract}

\section{Introduction}

The seminal reports by Newkome and Meijer about the hostguest properties of dendrimers have stimulated a lot of research in this area in the last two decades. ${ }^{1}$ Due to their tedious synthesis, however, the potential application of perfect dendrimers as carrier systems is limited. ${ }^{2}$ An alternative are hyperbranched polymers as reported by Kim and Webster. ${ }^{3}$ Although not perfectly branched, they exhibit properties very similar to those of the respective perfect dendrimers. Most importantly, they can be obtained with very controlled properties from a one-step polymerization reaction. ${ }^{4}$

The host-guest properties of hyperbranched polymers were evaluated using hyperbranched polyglycerol as a dendritic core within an amphiphilic structure. ${ }^{5}$ It has been shown that dendritic polyglycerol itself is able to solubilize guest

Institute of Chemistry and Biochemistry, Freie Universität Berlin, Takustr. 3, D-14195 Berlin, Germany. E-mail: haag@chemie.fu-berlin.de; Web: http://www.polytree.de; Fax: +49-30-838-53357; Tel: +49-30-838-52633

${ }^{b}$ Department of Chemistry, Faculty of Science, Lorestan University, Khoramabad, Iran ${ }^{c}$ Lab of Dendrimers and Biopolymers, Faculty of Chemistry, University of Tabriz, P. O. Box: 51664, Tabriz, Iran

${ }^{d}$ Institute of Pharmacy (Pharmacology and Toxicology), Freie Universität Berlin, 14195 Berlin, Germany

† Electronic supplementary information (ESI) available: See DOI: 10.1039/c4ra14619k molecules, however, transport and solubility are significantly improved by the attachment of one or more shells thereby forming core-shell architectures. ${ }^{6}$ These architectures have been investigated for use in various areas ranging from medical applications to catalysis. ${ }^{7}$

A third class are hybrid linear-dendritic systems in which one or more linear polymers are coupled randomly or in a defined manner to one or more dendritic components. ${ }^{8}$ In this case, both building blocks have a strong effect on each other's properties, e.g. the introduction of a dendritic part in a hybrid linear-dendritic copolymers decreases its viscosity while the introduction of the linear polymer increases the flexibility. In recent years, a number of such hybrid polymers have been reported. ${ }^{9,10}$

Polyglycerol is a biocompatible dendritic macromolecule obtained by ring-opening multi-branching polymerization. ${ }^{11}$ This polyether polyol is highly hydrophilic and exhibits a large number of hydroxy end groups which can be easily modified by a variety of organic transformations. Modification with hydrophobic compounds yields amphiphilic systems with a hydrophilic core and hydrophobic outer shell ${ }^{12}$ which should exhibit host-guest properties and can be designed as biodegradable nanocarrier systems.

Linear polymers like poly(lactic acid) (PLA), poly(glycolic acid) (PGA), poly( $\varepsilon$-caprolactone) (PCL) and poly(ethylene glycol) (PEG) are considered biocompatible polymers and have been 
applied in a wide range of applications from drug delivery to tissue engineering. Poly(lactic acid) is used for bioresorbable surgical sutures and is being investigated for other applications, e.g. in orthopedics, and wound closure. Drug delivery systems based on a hydrophilic core and PLA hydrophobic chains has been synthesized and used to deliver water soluble drugs recently. It has been found that hydrophobic shell is able to control rate of release of encapsulated drugs. ${ }^{13}$ Therefore, the incorporation of these biodegradable polymers into dendritic structures is an attractive way to obtain well-defined dendritic structures for biomedical applications. ${ }^{\mathbf{1 3 , 1 4}}$

Self-assembly of amphiphilic copolymers with polyglycerol core and hydrophobic PLA chains in aqueous solutions leads to nanoparticles with corona and core structure. Nanoparticles are able to encapsulate therapeutic agents such as proteins and release them in a controlled manner. ${ }^{14}$

Here we report on the synthesis and characterization of multiarm star copolymers (MSCs) which are composed of a polyglycerol core and poly(lactic acid) arms. Polyglycerol was used as a macroinitiator for the polymerization of lactide to generate the desired core-shell type architectures. The encapsulation of guest molecules and the dependence of the transport capacity on the polymer architecture were investigated in detail. The ability of MSCs to penetrate into the skin was also evaluated.

\section{Experimental}

\section{Characterization}

${ }^{1} \mathrm{H}$-NMR spectra were recorded in $\mathrm{CDCl}_{3}$ solution on a Bruker DRX 500 (500 MHz) apparatus with the solvent proton signal for reference. ${ }^{13} \mathrm{C}$-NMR spectra were recorded at $125.7 \mathrm{MHz}$ on the same instrument using the solvent carbon signal as a reference. All polymer NMR spectra were recorded at a concentration of $250 \mathrm{mg} \mathrm{mL} \mathrm{m}^{-1}$ of sample. The polymers number average molecular weights were calculated from the ${ }^{1} \mathrm{H}$-NMR data. The molecular weight distributions were determined by size exclusion chromatography (SEC) using Agilent 1100 and a PSS GRAL $100 \AA$ column connected to a differential refractometer, with RI and UV detector with chloroform as the mobile phase at $25{ }^{\circ} \mathrm{C}$. Poly(styrene) standard samples were used for calibration.

TGA measurements were recorded by a STA 409 apparatus (from Netzsch) in temperatures ranging from $50-650{ }^{\circ} \mathrm{C}$ with a $10{ }^{\circ} \mathrm{C} \min ^{-1}$ heating rate under nitrogen atmosphere. All UV measurements were performed on a 100 Specord spectrophotometer. IR measurements were performed using a Nicolet 320 FT-IR. Nile red amounts in the dermal layers of interest were determined using the fluorescence microscope BZ-8000 Keyence (Neu-Isenburg, Germany).

\section{Materials}

Dendritic polyglycerol $(\mathrm{DB}=60 \%$ ) was synthesized according to a procedure developed by Sunder et al. and modified by Türk et al. using ring-opening polymerization of glycidol monomers with a TMP core. ${ }^{11}$ Lactide was purchased from Aldrich and was recrystallized in dry toluene before usage. Stannous-2- ethylhexanoate, Congo red, Nile red and 5-ASA were purchased from Sigma Aldrich.

\section{General procedure for the preparation of multiarm star copolymers}

A solution of hPG in methanol was added to a polymerization ampule. Then methanol was evaporated under vacuum at $80{ }^{\circ} \mathrm{C}$ for $2 \mathrm{~h}$. After cooling, a solution of $\mathrm{Sn}(\mathrm{Oct})_{2}$ in toluene was added to the ampule and the toluene was evaporated under vacuum for 30 minutes at $40{ }^{\circ} \mathrm{C}$. Lactide monomer was then added to the ampule and the mixture placed under vacuum for $1 \mathrm{~h}$ and purged with argon three times. Then the ampule was sealed under vacuum and the mixture was stirred at $125^{\circ} \mathrm{C}$ for 2-4 h. After cooling, the polymerization ampule contents were dissolved in chloroform and filtered. The pure product was obtained by repeated precipitation of the polymer in cyclohexane and subsequent drying under vacuum at $50{ }^{\circ} \mathrm{C}$ for $1 \mathrm{~h}$.

IR: $3350(\nu \mathrm{OH}), \quad 2910,2820(\nu \mathrm{C}-\mathrm{H}), 1735 \quad(\nu \mathrm{C}=\mathrm{O})$, $1150(\nu \mathrm{C}-\mathrm{O}), \mathrm{cm}^{-1} \cdot{ }^{1} \mathrm{H}$ NMR $\left(\mathrm{CDCl}_{3}\right)$ : (1.25-1.9 $\left.\mathrm{CH}_{3}-\right)$, (2.65-2.9 $-\mathrm{OH}-)$, (3.2-4 - $\mathrm{CH}_{2}-\mathrm{O}-$ and $\left.-\mathrm{CH}_{2}-\mathrm{OH}\right),\left(4-4.5\right.$ PG- $\mathrm{CH}_{2}-\mathrm{OCO}$ and -CO-CHMe-OH), (-OCO-CHMe-OCO-). ${ }^{13} \mathrm{C} \mathrm{NMR}\left(\mathrm{CDCl}_{3}\right)$ : (17 $\left.\mathrm{CH}_{3}\right),\left(65-75-\mathrm{CH}_{2}^{-},-\mathrm{CH}-\right),(171 \mathrm{C}=\mathrm{O})$.

\section{General procedure for the encapsulation of Congo red}

A chloroform solution of the polymer with a concentration of $0.02 \mathrm{~g} \mathrm{~mL}^{-1}$ was prepared and stirred for $1 \mathrm{~h}$. An excess amount of Congo red was added to this solution and the mixture stirred for $2 \mathrm{~h}$ at room temperature. The solution was filtered, the filtrate was centrifuged at $11000 \mathrm{rpm}$ for $10 \mathrm{~min}$, and the clear solution decanted.

\section{General procedure for the encapsulation of Nile red}

A $5 \mathrm{mg} \mathrm{mL}{ }^{-1}$ Nile red stock solution in tetrahydrofuran (THF) was prepared. A certain amount of the stock solution was well mixed with $1 \mathrm{~mL}$ of THF solution of PG-PLA 12.5 and PG-PLA 6.25 at a concentration of $5 \mathrm{mg} \mathrm{mL} \mathrm{m}^{-1}$. The resulting solutions were added drop-wise into $4 \mathrm{~mL}$ of Milli $\mathrm{Q}$ water under stirring (1200 rpm). The formation of the Nile red loaded PG-PLA nanoassemblies occurred spontaneously. After stirring for 2 hours, THF then completely removed by dialysis against water using a dialysis tube (MWCO $=14000)$ for $24 \mathrm{~h}$. The unsolubilized Nile red was removed by centrifugation at $6000 \mathrm{rpm}$ for $10 \mathrm{~min}$. The final solution was appropriately concentrated using a Rotavapor at $37{ }^{\circ} \mathrm{C}$ under vacuum. Transport capacity was determined by UV using the method report in literature. ${ }^{15}$ Briefly, $0.2 \mathrm{~mL}$ of the aqueous solution of the Nile red loaded nanoparticles was freeze-dried and redissolved in $1 \mathrm{~mL}$ of methanol. The concentration of Nile red in methanol $(\mathrm{MeOH})$ was estimated using the molar extinction coefficient $(\varepsilon)$ of $45000 \mathrm{M}^{-1} \mathrm{~cm}^{-1}$ at $552 \mathrm{~nm}$.

\section{General procedure for the encapsulation of 5-ASA}

A chloroform solution of the polymer with a certain concentration was prepared and stirred for $1 \mathrm{~h}$. The guest molecule (5-ASA) (excess) was dissolved in DMF and this solution was 
added to the chloroform solution of the polymer. The mixture was stirred for $2 \mathrm{~h}$, the solvent was evaporated under vacuum at $100{ }^{\circ} \mathrm{C}$, and a brown solid compound was obtained. Then chloroform $(15 \mathrm{~mL})$ was added and the mixture was stirred for $1 \mathrm{~h}$, then filtered with a $0.4 \mu \mathrm{m}$ filter and a clear solution containing host-guest system was obtained.

\section{Particle size analysis}

The sizes of nanocarriers were analyzed with dynamic light scattering experiments on a Zetasizer Nano from Malvern using a $4 \mathrm{~mW} \mathrm{He}-\mathrm{Ne}$ laser (633 $\mathrm{nm}$ wavelength) with a fixed detector angle of $173^{\circ}$. The measurement was performed at $25{ }^{\circ} \mathrm{C}$ and was started $10 \mathrm{~min}$ after the cuvette was placed in the DLS apparatus to allow the temperature to equilibrate. About $1 \mathrm{~mL}$ of the sample was transferred to a dust free light scattering cell and the temperature was controlled within $\pm 0.02{ }^{\circ} \mathrm{C}$.

\section{Preparation of samples for transmission electron microscopy}

A chloroform solution of guest molecules encapsulated by nanocarriers was dropped on the graphite layer and solvent was evaporated at room temperature.

\section{Skin penetration studies}

To characterize the dermal drug delivery efficiency of the multiarm star copolymers, the skin absorption of the loaded fluorescence dye Nile red was evaluated by validated test procedures using the Franz cell set-up and picture analysis. ${ }^{16,17}$ Nile red loaded multiarm star copolymers $\mathrm{PG}_{8000}-\mathrm{PLA}_{12.5}$ and $\mathrm{PG}_{8000}-\mathrm{PLA}_{6.25}$ as well as conventional base cream were tested in parallel using human skin of the same donor. ${ }^{16}$ Nile red incorporated into base cream $(0.001 \%)$ served as a reference in the skin penetration studies. Therefore, the dye was dispersed in paraffin oil droplets and subsequently was incorporated into base cream. ${ }^{18}$

Prior to the experiment, human skin was thawed and discs of $2 \mathrm{~cm}$ diameter were punched and mounted onto static-type Franz cells (diameter $15 \mathrm{~mm}$, volume $12 \mathrm{~mL}$, PermeGear Inc., Bethlehem, PA, USA) with the horny layer facing the air and the dermis having contact with the receptor fluid phosphate buffered saline pH 7.4 (PBS; $33.5^{\circ} \mathrm{C}$, skin surface temperature about $32{ }^{\circ} \mathrm{C}$ ) stirred at $500 \mathrm{rpm}$. After $30 \mathrm{~min}, 35 \mu \mathrm{L}$ of the test formulations was applied onto the skin surface (finite-dose approach) and remained there for $6 \mathrm{~h}$. Subsequently, the skin was removed from the Franz cells, and the skin surface was gently cleaned using PBS. Afterwards, treated skin areas were punched, embedded in tissue freezing medium (Jung, Nussloch, Germany) and stored in Peel-Aways (Polyscience, Eppelheim, Germany) at a temperature of $-80{ }^{\circ} \mathrm{C}$.

For data evaluation, the skin discs were cut into vertical slices of $8 \mu \mathrm{m}$ thickness using a freeze microtome (Frigocut $2800 \mathrm{~N}$, Leica, Bensheim, Germany). The slices were subjected to normal light and fluorescence light. Nile red amounts in the dermal layers of interest were determined using the fluorescence microscope.

\section{Results and discussion}

Starting with water-soluble hydrophilic hPG (degree of branching $=60 \%$ ) as macroinitiator for the polymerization of lactide (Scheme 1), new biocompatible core-shell systems were obtained. Since poly(lactic acid) (PLA) is hydrophobic, the properties of the resulting copolymers changed completely and were dependent on the size of the PLA shell. Two different molecular weights of polyglycerol $\left(\mathrm{hPG}_{8000}\right.$ and $\left.\mathrm{hPG}_{2400}\right)$ as well as different amounts of lactide per $\mathrm{OH}$ group of polyglycerol $([\mathrm{LA}] /[\mathrm{OH}])$ were chosen to prepare the MSCs.

\section{Characterization of PG-PLA multiarm star copolymers}

Fig. 1 shows the ${ }^{1} \mathrm{H}-\mathrm{NMR}$ spectra of a MSCs consisting of a dendritic $\mathrm{hPG}_{2400}$ core and PLA arms (see ESI† for $\mathrm{hPG}_{8000}$ ). Signals of the PLA chains appear at 1.25-1.90 ppm and 5.00-5.30 ppm for protons of methyl and - $\mathrm{CH}-$ groups, respectively. The signals of the hPG protons appear at 2.65-2.90 ppm and 3.20-4.00 ppm for protons of unreacted $\mathrm{OH}$ groups and methylene groups, respectively. The region between 4.00-4.50 ppm shows overlapping signals of the hPG core and PLA. The ratio of the peak area of PLA to hPG moiety directly depends on the $[\mathrm{LA}] /[\mathrm{OH}]$ ratio (Fig. 1). At high $[\mathrm{LA}] /[\mathrm{OH}]$ ratios (for $\mathrm{hPG}_{8000}$ see ESI $\dagger$ ), the signals of the hPG
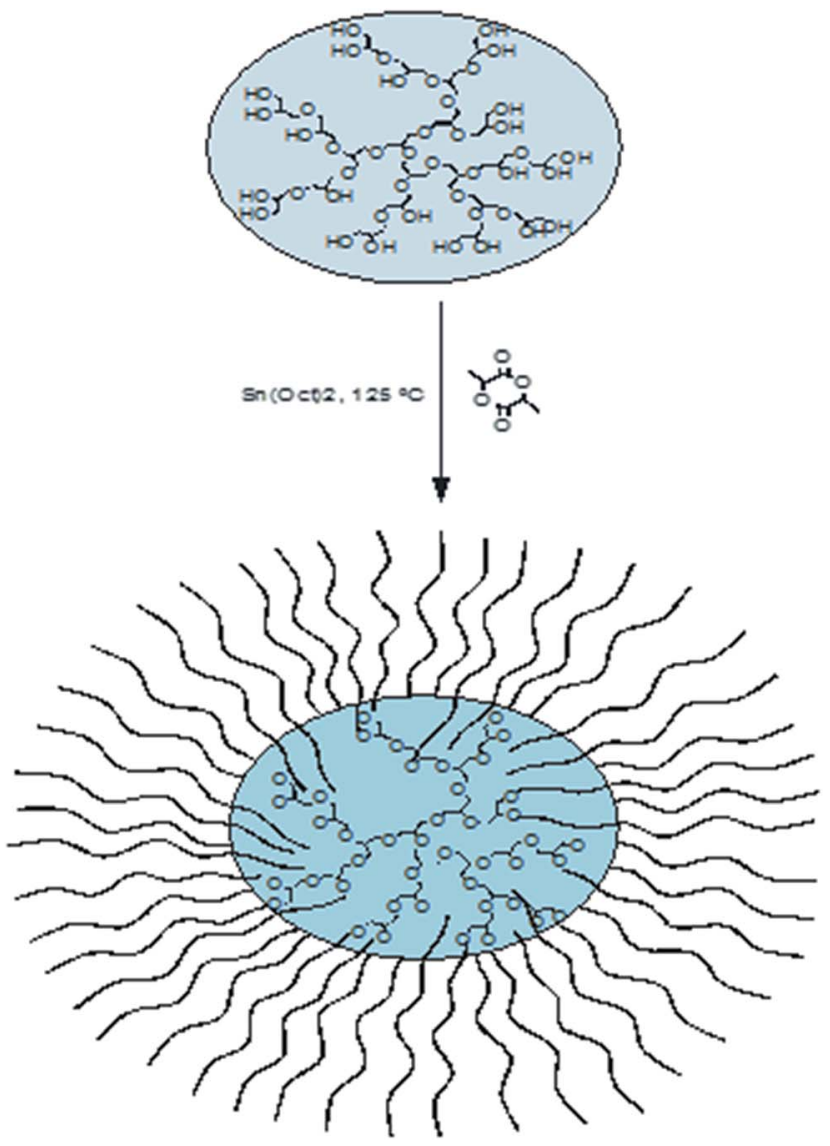

Scheme 1 Synthesis of multiarm star copolymers consisting of a polyglycerol core and poly(lactic acid) arms. 


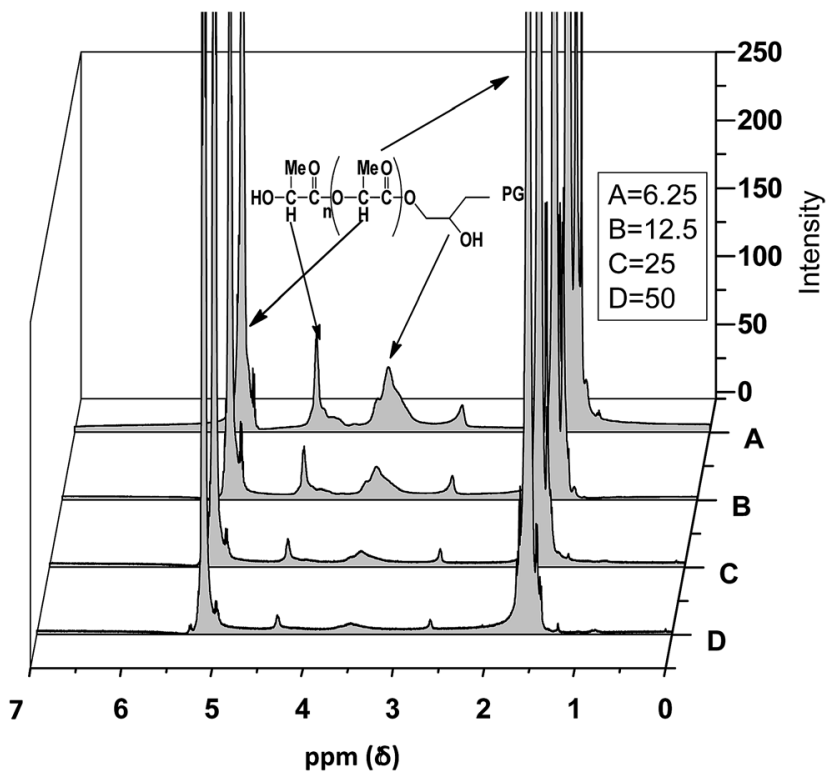

Fig. $1{ }^{1} \mathrm{HNMR}$ spectra of $\mathrm{PG}_{2400}-\mathrm{PLA}$ multiarm star copolymers, synthesized using $6.25,12.5,25$ and $50[\mathrm{LA}] /[\mathrm{OH}]$ ratios, in $\mathrm{CDCl}_{3}$.

moiety disappear due to lacking sensitivity. In the IR spectra, intensity of the $\mathrm{OH}$ absorbance band decrease upon increasing the $[\mathrm{LA}] /[\mathrm{OH}]$ ratio (see ESI $\dagger$ ). Both observations prove the growth of the number of PLA arms on the free $\mathrm{OH}$ groups of hPG resulting in less and less free $\mathrm{OH}$ groups. ${ }^{1} \mathrm{H}-\mathrm{NMR}$ spectra of star copolymers are used to determine some of the characteristics such as molecular weight, arm number, DP, and free $\mathrm{OH}$ groups. An example for the calculation of these characteristics is given in the ESI $\dagger$ for the star copolymer with $\mathrm{hPG}_{8000}$ core and $[\mathrm{LA}] /[\mathrm{OH}]=6.25$.

The characteristics of the multiarm star copolymers with dendritic $\mathrm{hPG}_{2400}$ and $\mathrm{hPG}_{8000}$ cores are given in Tables 1 and 2. The molecular weight, the number of arms, and DP of copolymers increased with increasing the $[\mathrm{LA}] /[\mathrm{OH}]$ ratio for both $\mathrm{hPG}_{2400}$ and $\mathrm{PG}_{8000}$ series. An almost linear relationship is observed between the molecular weight of copolymers and the $[\mathrm{LA}] /[\mathrm{OH}]$ ratio used. By using this diagram an estimation of the required $[\mathrm{LA}] /[\mathrm{OH}]$ ratio for the preparation of a star copolymer with a certain molecular weight can be given (see ESI $\dagger$ ).

GPC measurements were performed to determine the polydispersity of the copolymers, the change of their molecular weights upon polymerization of lactide monomer, and especially to assure the monomodality of the final products and therefore the absence of homopolymers. The results for multiarm star copolymers with dendritic $\mathrm{hPG}_{8000}$ cores are shown in Fig. 2 (see Fig. $\mathrm{S} 4 \mathrm{~b} \dagger$ for $\mathrm{hPG}_{2400}$ series). In both series, the elution time decreases with increasing $[\mathrm{LA}] /[\mathrm{OH}]$ ratio, which shows the growth of PLA arms on the dendritic cores and the polydispersity of the star copolymers to be between 1.5-2.5. All of the GPC diagrams are also monomodal which proves the absence of homopolymers or other impurities.

The conjugation of flexible polymers to linear PLA results in block copolymers with modified physicochemical properties. Accordingly, the conjugation of PLA with the flexible hPG scaffold brings about copolymers with interesting thermal behaviours. Both the onset and maximum decomposition temperatures of star copolymers depended on their molecular weight (See Fig. S5a $\dagger$ ). Table S1 $\dagger$ lists the temperatures for $20 \%$ and $50 \%$ weight loss $(T 20 \%$ and $T 50 \%)$ of multiarm star copolymers containing $\mathrm{hPG}_{8000}$ core and shows that the thermal stability significantly increases from $\mathrm{PG}_{8000}-\mathrm{PLA}_{6.25}$ to $\mathrm{PG}_{8000}-\mathrm{PLA}_{12.5}$. A slight increase is observed for $\mathrm{PG}_{8000}-\mathrm{PLA}_{25}$ compared to $\mathrm{PG}_{8000}-\mathrm{PLA}_{12.5}$, however, an additional increase of the $[\mathrm{LA}] /[\mathrm{OH}]$ ratio does not change the thermal stability further. For the series containing the $\mathrm{hPG}_{2400}$ core even less significant changes were observed (see Fig. S5b †े).

\section{Transport and encapsulation possessions}

The potential of core-shell architectures to encapsulate and transport guest molecules was already investigated ${ }^{19}$ and hPG as a special case was studied very well. ${ }^{20,21}$ The linear-dendritic amphiphilic copolymers presented here, were synthesized to modify the encapsulation properties of polyglycerol thereby generating a degradable system for the encapsulation of hydrophilic compounds. Congo red was selected as a model guest compound. The preparation of the host-guest systems was accomplished by dissolving the copolymer in chloroform and adding an excess amount of the guest molecule. Fig. 3 shows a picture of Congo red encapsulated in $\mathrm{PG}_{2400}-\mathrm{PLA}$ multiarm star copolymers with different shells. The solutions were prepared with the same weight percent of polymers resulting in a decreasing molar concentration for the higher molecular weight polymers. Clearly, the intensity of the red color from $\mathrm{PG}_{2400}-\mathrm{PLA}_{6.25}$ to $\mathrm{PG}_{2400}-\mathrm{PLA}_{50}$ increases, confirming an increment in the amount of encapsulated Congo red. Therefore, it can be stated that the thickness of the hydrophobic shell is one of the major factors dominating the transport capacity of nanocarriers.

The transport capacity of multiarm star copolymers containing $\mathrm{hPG}_{8000}$ and $\mathrm{hPG}_{2400}$ cores was investigated by UV-vis spectroscopy (Fig. S7 and S8†). The intensity of $\lambda_{\max }$ and

Table 1 Characterization of $\mathrm{PG}_{2400}-\mathrm{PLA}$ multiarm star copolymers

\begin{tabular}{lllllrrr}
\hline Sample & {$[\mathrm{LA} / \mathrm{OH}]$} & Conversion & $M_{\mathrm{n}}(\mathrm{NMR})$ & $\mathrm{DP}$ & $M_{\mathrm{w}} / M_{\mathrm{n}}$ & Arms & Free OH groups \\
\hline 1 & 6.25 & $89 \%$ & $3 \times 10^{4}$ & 8 & 1.61 & 19 & 14 \\
2 & 12.5 & $94 \%$ & $5 \times 10^{4}$ & 16 & 1.49 & 20 & 13 \\
3 & 25 & $96 \%$ & $10 \times 10^{4}$ & 23 & 1.55 & 30 & 3 \\
4 & 50 & $98 \%$ & $20 \times 10^{4}$ & 48 & 1.76 & 30 & 3
\end{tabular}


Table 2 Characterization of $\mathrm{PG}_{8000}$-PLA multiarm star copolymers

\begin{tabular}{lccccccc}
\hline Sample & {$[\mathrm{LA} / \mathrm{OH}]$} & Conversion & $M_{\mathrm{n}}(\mathrm{NMR})$ & $\mathrm{DP}$ & $M_{\mathrm{w}} / M_{\mathrm{n}}$ & Arms & Free OH groups \\
\hline 1 & 6.25 & $88 \%$ & $9 \times 10^{4}$ & 9 & 1.77 & 65 & 44 \\
2 & 12.5 & $93 \%$ & $15 \times 10^{4}$ & 15 & 1.54 & 69 & 40 \\
3 & 25 & $95 \%$ & $23 \times 10^{4}$ & 20 & 1.67 & 80 & 29 \\
4 & 50 & $98 \%$ & $64 \times 10^{4}$ & 45 & 2.51 & 99 & 10 \\
5 & 100 & $99 \%$ & $139 \times 10^{4}$ & 96 & 1.65 & 101 & 8
\end{tabular}

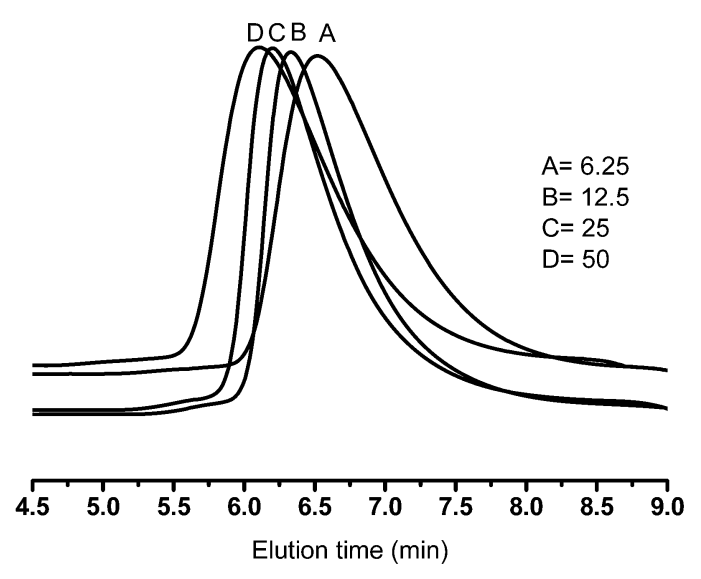

Fig. 2 GPC plots for $\mathrm{PG}_{8000}-\mathrm{PLA}$ multiarm star copolymers with $[\mathrm{LA}] /[\mathrm{OH}]$ ratios of (A) 6.25, (B) 12.5, (C) 25 and (D) 50.

therefore the amount of encapsulated guest molecules directly depends on the number and length of the arms. Comparison of the transport capacity of the different carriers shows that for the $\mathrm{PG}_{8000}-\mathrm{PLA}$ series it is much higher than that of the $\mathrm{PG}_{2400}$-PLA analogues (Fig. 4).

Since the number of arms is much higher in case of the $\mathrm{PG}_{8000}$-PLA than for the $\mathrm{PG}_{2400}$-PLA series, while their DP is comparable, the large difference between the TC of these two series seems to be rather related to the number of their arms than their length. On the other hand $\mathrm{PG}_{8000}$-PLA series with a bigger hydrophilic core interact with the hydrophilic guest molecules better than smaller one in the case of $\mathrm{PG}_{2400}-\mathrm{PLA}$ series.

The UV spectra and TC plot show that the difference between the amount of encapsulated guest molecules by $\mathrm{PG}_{2400}-\mathrm{PLA}_{12.5}$ and $\mathrm{PG}_{2400}-\mathrm{PLA}_{25}$ is higher than in other

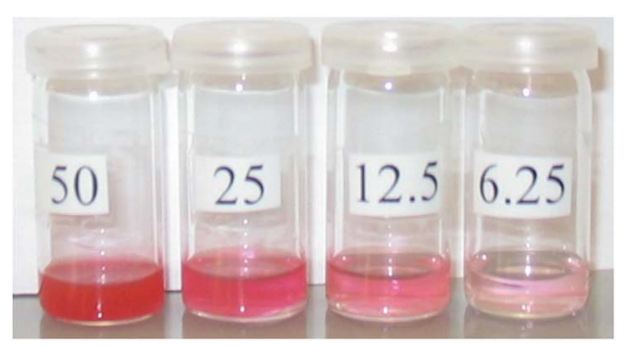

Fig. 3 Photograph of encapsulated Congo red by $\mathrm{PG}_{2400}-\mathrm{PLA}$ multiarm star copolymers with different $[\mathrm{LA}] /[\mathrm{OH}]$ ratios at the same nanocarrier concentration. samples in this series which is also reflected by the color difference of these two samples (Fig. S6 and S8 $\dagger$ ). When comparing the number of PLA arms in the $\mathrm{hPG}_{2400}$ series (see Table 1), a significant increase can be observed between the polymers with $[\mathrm{LA}] /[\mathrm{OH}]$ ratios of 6.25 and 12.5 (19 and 20 arms, respectively) compared to those with a higher $[\mathrm{LA}] /[\mathrm{OH}]$ ratio $(30$ arms). This result shows that probably a critical number of arms is required for aggregation, which in turn is necessary to achieve a good loading.

The TC of the nanocarriers described here also depends on their concentration in solution. In order to investigate the effect of concentration on the transport capacity, several concentrations of star copolymers in chloroform were prepared and their TC was evaluated. Fig. 5 depicts the relation between the concentration of $\mathrm{PG}_{8000}-\mathrm{PLA}_{12.5}$ and the TC. While in dilute solutions an inverse relation between $\mathrm{TC}$ and concentration was observed, at higher concentrations the TC was constant, probably due to the formation of aggregates.

After the successful loading of Congo red as a hydrophilic guest molecule, the ability of the multiarm copolymers to encapsulate 5-ASA as a poorly water soluble drug was evaluated. Fig. S9† shows UV spectra of the chloroform solution of 5-ASA encapsulated in the multiarm copolymers $(0.002 \mathrm{w} / \mathrm{v})$ with the $\mathrm{hPG}_{2400}$ core. In this case there is an almost linear correlation between the TC and molecular weight of copolymers ([LA] $/[\mathrm{OH}])$.

In order to evaluate the effect of the structure of arms on the encapsulation properties of copolymers, $\mathrm{PG}_{8000}-\mathrm{PCL}$ with a

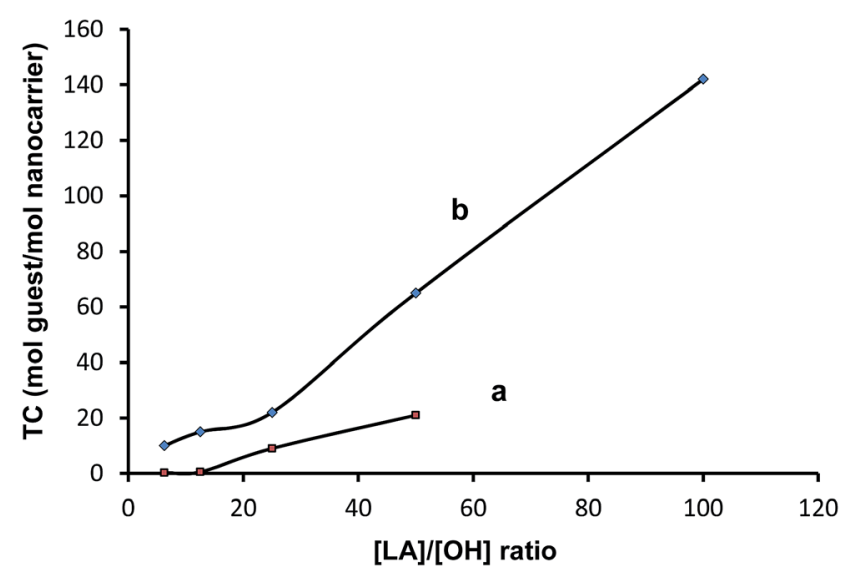

Fig. 4 Transport capacity [mol guest/mol nanocarrier] versus $[\mathrm{LA}] /[\mathrm{OH}]$ ratio for (a) $\mathrm{PG}_{2400}-\mathrm{PLA}$ and (b) $\mathrm{PG}_{8000}-\mathrm{PLA}$ multiarm star copolymers. 


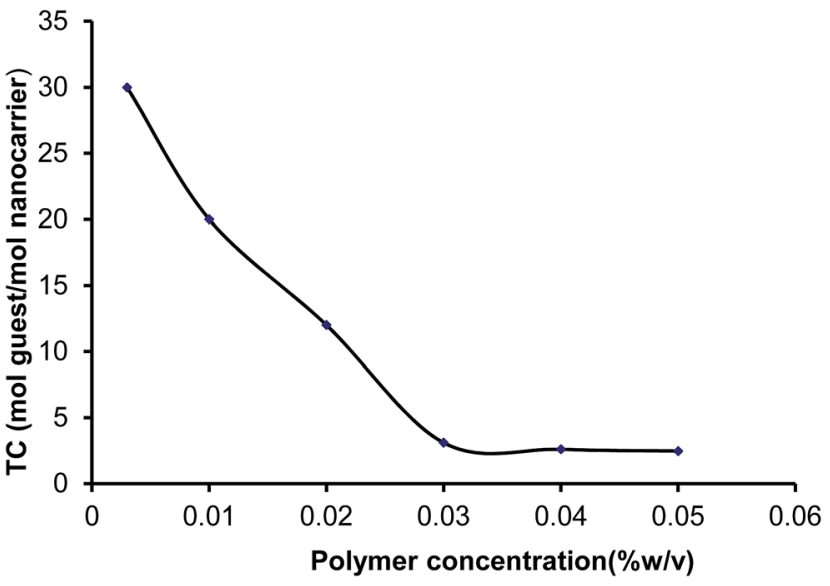

Fig. 5 Transport capacity of $\mathrm{PG}_{8000}-\mathrm{PLA} \mathrm{A}_{12.5}$ multiarm star copolymer versus concentration in chloroform.

$[\mathrm{CL}] /[\mathrm{OH}]=25$ (i.e. $\mathrm{PG}_{8000}-\mathrm{PC}_{25}$ ) were synthesized and their ability to encapsulate 5-ASA was compared with that of the PG-PLA nanocarriers. They were able to encapsulate 5-ASA (Fig. S11†) but with a lower transport capacity than $\mathrm{PG}_{8000}-\mathrm{PLA}_{25}$, probably due to the lower polarity and higher flexibility of the PCL arms. The amount of the loaded 5-ASA in all PG-PLA copolymers was determined. Fig. $6 a$ and $b$ show the relation between the $[\mathrm{LA}] /[\mathrm{OH}]$ ratio and the TC of the PG-PLA copolymers. It was found that the size of the hPG core has a big influence on the TC of copolymers, because in all cases the copolymers containing a $\mathrm{hPG}_{8000}$ core showed a higher $\mathrm{TC}$ than those with the $\mathrm{hPG}_{2400}$ core. An exception was $\mathrm{PG}_{8000}-\mathrm{PLA}_{100}$, since its $\mathrm{TC}$ was lower than that for $\mathrm{PG}_{8000}-\mathrm{PLA}_{50}$. Since such behaviour was not observed for Congo red, it can be found that there is a relation between the structure of the guest molecule and TC in the high $[\mathrm{LA}] /[\mathrm{OH}]$ ratios. Long hydrophobic arms cover the core completely and diminish interactions between polar guest molecules and this part in the case of $\mathrm{PG}_{8000}-\mathrm{PLA}_{100}$.

The size of nanocarriers containing loaded guest molecules was investigated with different spectroscopy and microscopy

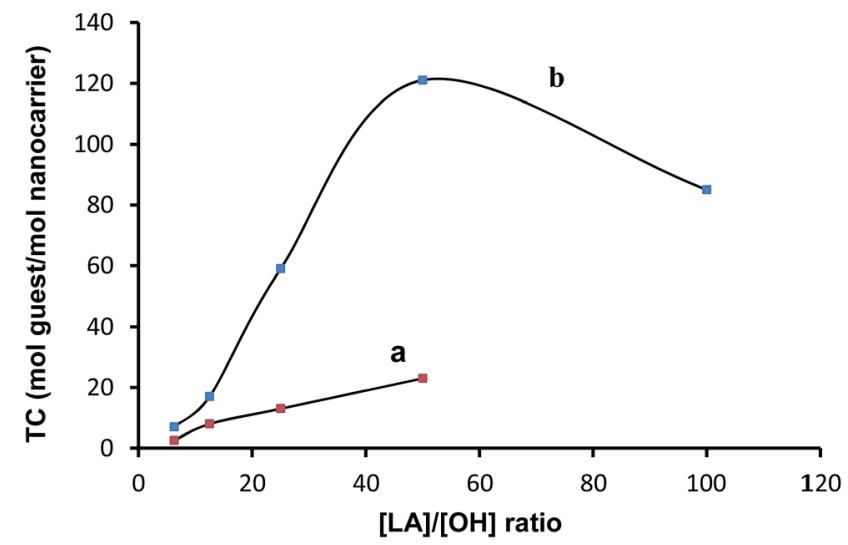

Fig. 6 The amount of the loaded 5-ASA (TC) against $[\mathrm{LA}] /[\mathrm{OH}]$ ratio (a) for $\mathrm{PG}_{2400}-\mathrm{PLA}$ and (b) for $\mathrm{PG}_{8000}-\mathrm{PLA}$ multiarm star copolymers.

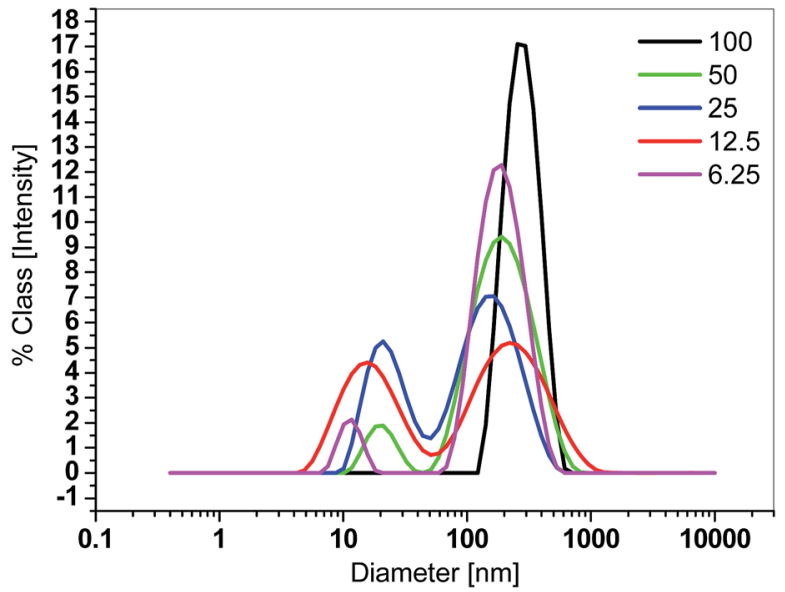

Fig. 7 DLS diagrams of $\mathrm{PG}_{8000}$-PLA nanocarriers containing encapsulated 5-ASA.

methods. Fig. 7 shows the dynamic light scattering (DLS) diagrams of $\mathrm{PG}_{8000}$-PLA nanocarriers containing encapsulated 5-ASA. The concentration of nanocarriers is $2 \mathrm{~g} \mathrm{~L}^{-1}$.

The appearance of two different sizes in all cases shows that nanocarriers aggregate to form bigger particles. ${ }^{22}$ The size of the nanoparticles is increased with increasing molecular weight of the nanocarrier. An exception is PG-PLA ${ }_{6.25}$ for which DLS experiments show larger sizes, because of its short PLA arms and poor solubility in chloroform which leads to the formation of big aggregates. This does not happen in case of PG-PLA 100 with very long PLA arms, thereby leading to a very low polydispersity compared to the other systems (Fig. S12 and S13†). A similar behaviour is observed for nanocarriers containing a $\mathrm{PG}_{2400}$ core (Fig. S14†).

In order to obtain more information concerning size of nanoparticles in solution, DLS diagrams of chloroform solutions of $\mathrm{PG}_{8000}-\mathrm{PLA}_{25}$ with different concentrations were recorded and evaluated. Fig. 8 shows the results of these

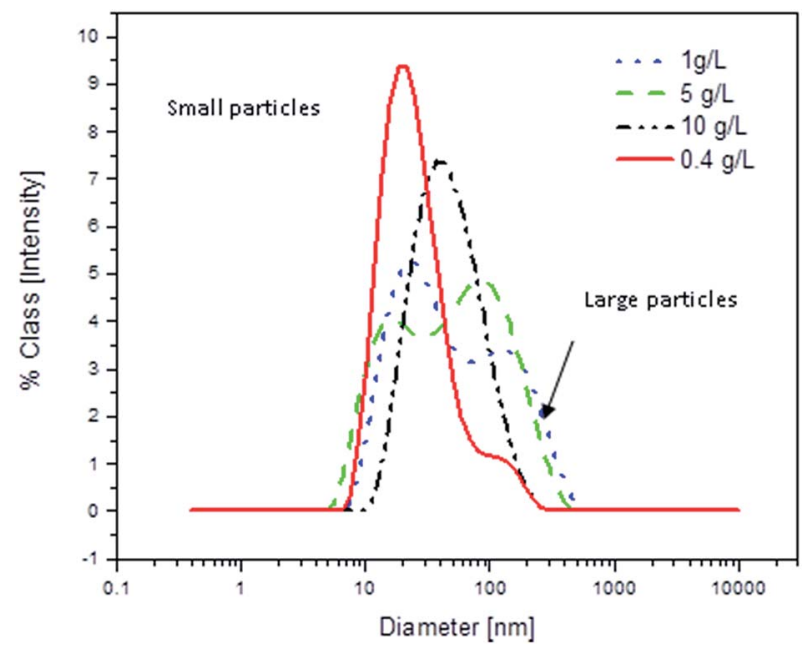

Fig. 8 The effect of concentration on the size of $P G_{8000}-P L A_{25}$ nanocarrier aggregates. 

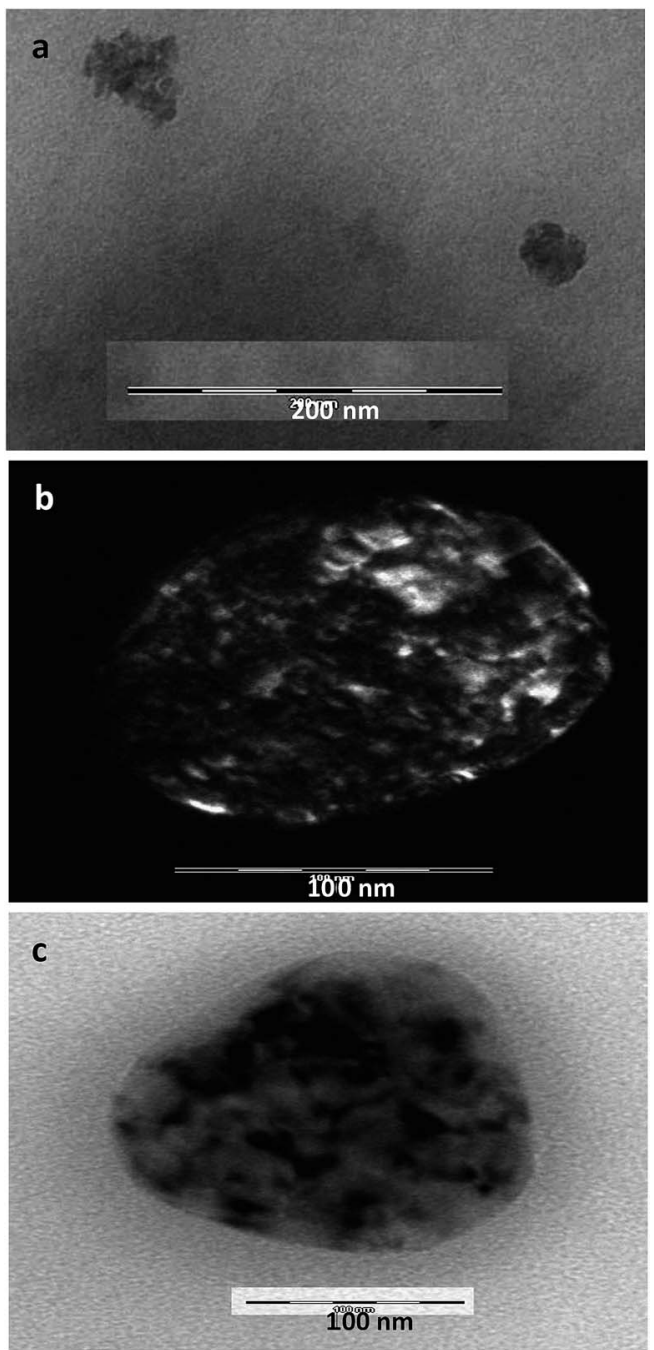

Fig. 9 TEM images of $\mathrm{PG}_{8000}-\mathrm{PLA} \mathrm{A}_{25}$ nanocarriers obtained from their chloroform solutions with concentrations of (a) $0.4 \mathrm{~g} \mathrm{~L}^{-1}$, (b) $1 \mathrm{~g} \mathrm{~L}^{-1}$, and (c) $5 \mathrm{~g} \mathrm{~L}^{-1}$.

experiments. At low concentration $\left(0.4 \mathrm{~g} \mathrm{~L}^{-1}\right)$ DLS measurements show mainly single size for this nanocarrier (about $15 \mathrm{~nm}$ ) and the intensity of large particles (aggregates) is very low. However, at higher concentrations self-assembly is more likely and the intensity of large particles is enhanced until at a concentration of $10 \mathrm{~g} \mathrm{~L}^{-1}$ only one size for large particles is observed. These results demonstrate the dependence of the size of the nanocarrier aggregates on the concentration and show that unimolecular nanocarriers can only be observed at low concentrations.

For the verification of the DLS results, TEM images of nanocarriers were recorded. Fig. 9a-c show TEM images of $\mathrm{PG}_{8000}-\mathrm{PLA}_{25}$ nanocarriers prepared from their chloroform solutions with concentrations of $0.4,1$, and $5 \mathrm{~g} \mathrm{~L}^{-1}$, respectively.

It can be seen that even at low concentration $\left(0.4 \mathrm{~g} \mathrm{~L}^{-1}\right.$, Fig. 10a) (Fig. S15a†) aggregates with a size of 40-50 nm which are composed of several smaller particles are formed by selfassembly. At a concentration of $1 \mathrm{~g} \mathrm{~L}^{-1}$ (Fig. 9b) (Fig. S15b the nanocarrier aggregates are significantly bigger with sizes of about $150 \mathrm{~nm}$. At even higher concentration $\left(5 \mathrm{~g} \mathrm{~L}^{-1}\right)$ the size of the aggregates does not change any more (Fig. 9c and S15c and $\mathrm{d} \dagger)$, but the type of aggregation is different. The electron beam image shows a relatively crystalline phase for aggregates at $1 \mathrm{~g} \mathrm{~L}^{-1}$ (Fig. 10a). At higher concentrations (5 $\left.\mathrm{g} \mathrm{L}^{-1}\right)$, the electron beam image shows that the aggregates are highly crystalline (Fig. 10b).

In order to investigate the ability of the prepared PG-PLA nanocarriers to transport hydrophobic guest molecules into the skin, we compared the skin penetration of Nile red $(0.001 \% \mathrm{w} / \mathrm{w})$ loaded onto $\mathrm{PG}_{8000}-\mathrm{PLA}_{6.25}$ and $\mathrm{PG}_{8000}-\mathrm{PLA}_{12.5}$ nanocarriers and conventional base cream $(0.001 \% \mathrm{w} / \mathrm{w})$. Microscopy evaluation showed that both $\mathrm{PG}_{8000}-\mathrm{PLA}_{6.25}$ and $\mathrm{PG}_{8000}-\mathrm{PLA}_{12.5}$ nanocarriers significantly enhanced the uptake of Nile red in the viable epidermis and even in deeper dermal layer (Fig. 11a and b), $\mathrm{PG}_{8000}-\mathrm{PLA}_{6.25}$ being superior. In contrast, following the application of the conventional cream, Nile red was exclusively detected in the stratum corneum and not in deeper dermal layers (Fig. 11c). One possible reason is the smaller particle size of $\mathrm{PG}_{8000}-\mathrm{PLA}_{6.25}$ but this is still under investigation. Taken together, these results are a first hint that multiarm star copolymers might be promising candidates for dermal delivery of therapeutic agents and demonstrates once more that slight structural variations between nanoparticles may significantly affect their drug delivery efficiency.
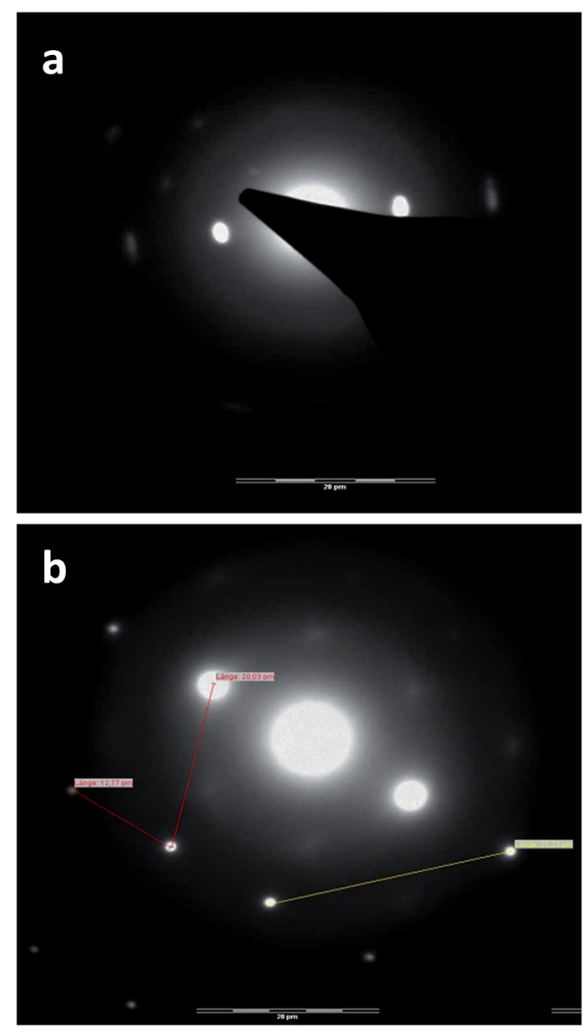

Fig. 10 Electron beam images of $\mathrm{PG}_{8000}-\mathrm{PLA}_{25}$ nanocarriers obtained from their chloroform solutions with concentrations of (a) $1 \mathrm{~g} \mathrm{~L}^{-1}$ and (b) $5 \mathrm{~g} \mathrm{~L}^{-1}$. 

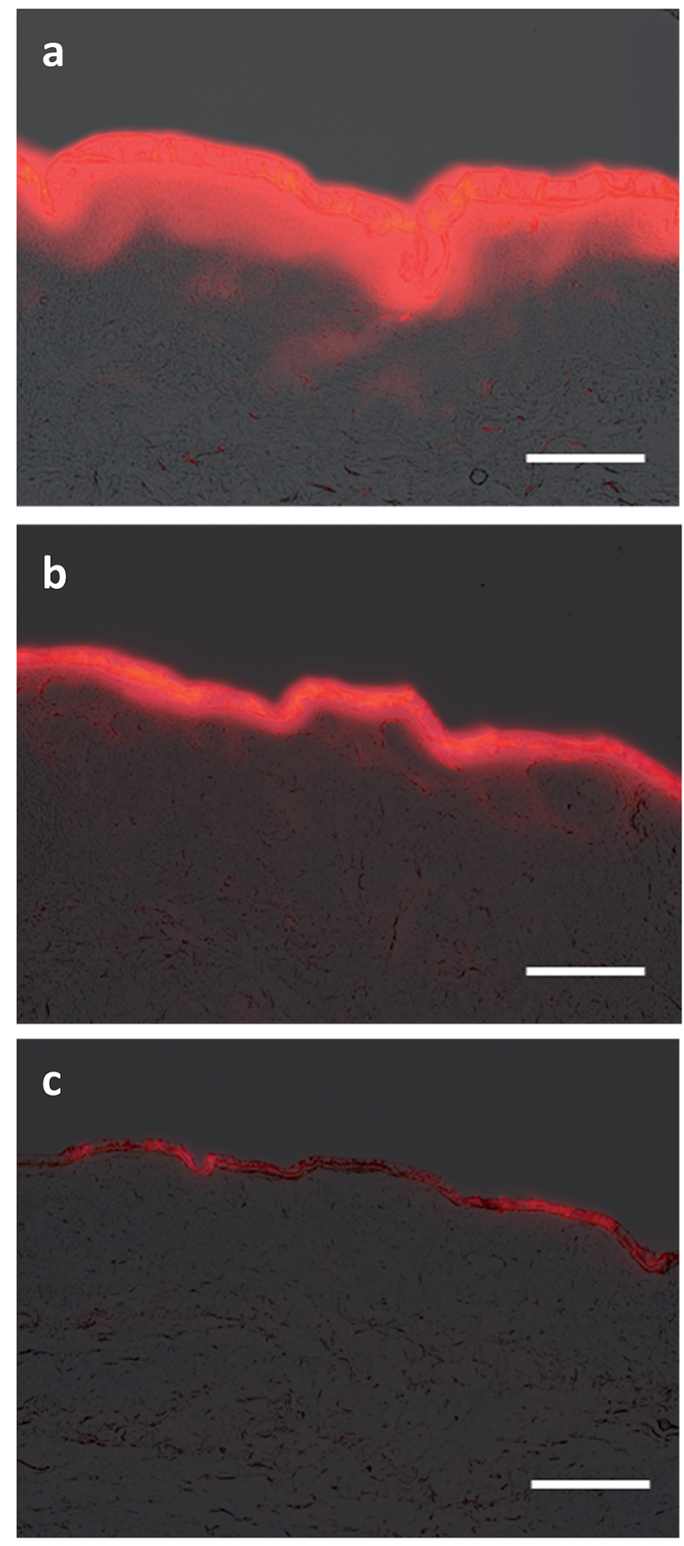

Fig. 11 Representative fluorescence microscopy images of human skin treated with (a) Nile red-loaded (0.001\%) $P G_{8000}-P L A_{6.25}$ nanocarrier; (b) Nile red-loaded (0.001\%) $\mathrm{PG}_{8000}-\mathrm{PLA}_{12.5}$ nanocarrier and (c) conventional base cream containing $0.001 \%$. Scale bar $=50 \mu \mathrm{m}$.

\section{Conclusions}

Here we described multiarm star nanocarriers that possess a defined core-shell-type architecture and have a high transport capacity for encapsulation of various guest molecules. These nanocarriers were synthesized via simple grafting polymerization of lactone monomers from the hydroxy groups of hyperbranched polyglycerol.

We observed that the number of PLA arms is the dominating factor to achieve a high transport capacity. The bigger $\mathrm{hPG}_{8000}$ core has more $\mathrm{OH}$ groups available for functionalization with PLA and therefore nanocarriers with a higher transport capacity were obtained. Also the size and transport capacity of these core-shell architectures were strongly dependent on their concentration in solution. Initial skin penetration tests show that these core-shell nanocarriers are able to transport Nile red as a model therapeutic agent through this complex biological barrier.

\section{Acknowledgements}

We thank the BMBF (IGST project) and the SFB 1112 for financial support.

\section{Notes and references}

1 G. R. Newkome, C. N. Moorefield, G. R. Baker, A. L. Johnson and R. K. Behera, Angew. Chem., Int. Ed. Engl., 1991, 30, 1176; G. R. Newkome, B. D. He, E. Woosley, C. N. Moorefield, R. Güther, G. R. Baker, G. H. Escamilla, J. Merrill and H. Luftmann, J. Chem. Soc., Chem. Commun., 1996, 2737; J. F. G. A. Jansen, E. M. M. de Brabander-van den Berg and E. W. Meijer, Science, 1994, 266, 1226; J. F. G. A. Jansen and E. W. Meijer, J. Am. Chem. Soc., 1995, 117, 4417; S. Stevelmans, J. C. M. van Hest, J. F. G. A. Jansen, D. F. A. J. van Boxtel, E. M. M. de Brabander-van den Berg and E. W. Meijer, J. Am. Chem. Soc., 1996, 118, 7398; M. W. P. L. Baars and E. W. Meijer, Top. Curr. Chem., 2000, 210, 131; M. W. P. L. Baars, P. E. Froehling and E. W. Meijer, Chem. Commun., 1997, 1959.

2 E. M. M. Brabender and E. W. Meijer, Angew. Chem., Int. Ed. Engl., 1993, 32, 1308; V. Percec, P. Chu, G. Ungar and J. Zhou, J. Am. Chem. Soc., 1995, 117, 11441; S. H. Medina and M. E. El-Sayed, Chem. Rev., 2009, 109, 3141.

3 Y. H. Kim and O. W. Webster, Polym. Prepr., 1988, 29, 310; Y. H. Kim and O. W. Webster, Macromolecules, 1992, 25, 5561.

4 Y. Segawa, T. Higashihara and M. Ueda, Polym. Chem., 2013, 4, 1746; D. Yan, C. Gao and H. Frey, Hyperbranched Polymers: Synthesis, Properties and Applications, John Wiley, (NY), 2011. 5 A. Sunder, M. Krämer, R. Hanselmann, R. Mülhaupt and H. Frey, Angew. Chem., 1999, 111, 3758; Angew. Chem., Int. Ed., 1999, 38, 3552; R. Haag, M. Krämer, J.-F. Stumbé and H. Kautz, Polym. Mater.: Sci. Eng., 2001, 84, 69; S.-E. Stiriba, H. H. Kautz and H. Frey, J. Am. Chem. Soc., 2002, 124, 9698.

6 M. Krämer, J.-F. Stumbé, H. Türk, S. Krause, A. Komp, L. Delineau, S. Prokhorova, H. Kautz and R. Haag, Angew. Chem., 2002, 114, 4426; Angew. Chem., Int. Ed., 2002, 41, 4252; T. Ooya, J. Lee and K. Park, Bioconjugate Chem., 2004, 15, 1221; S. Küchler, M. R. Radowski, T. Blascke, M. Dathe, J. Plendl, R. Haag, M. Schäfer-Korting and K. D. Krämer, Eur. J. Pharm. Biopharm., 2009, 71, 243.

7 H. Frey and R. Haag, Rev. Mol. Biotechnol., 2002, 90, 257; R. Haag, Angew. Chem., 2004, 116, 280; Angew. Chem., Int. Ed., 2004, 43, 278; I. N. Kurniasih, H. Liang, K. Kumar, A. Mohr, S. K. Sharma, J. P. Rabe and R. Haag, J. Mater. Chem. B, 2013, 1, 3569; M. Calderon, M. A. Quadir, S. K. Sharma and R. Haag, Adv. Mater., 2010, 22, 190. 
8 J. M. J. Fréchet, Science, 1994, 263, 1710; H. Namazi and M. Adeli, Eur. Polym. J., 2003, 39, 1491; M. Adeli, S. Beyranvand and M. Hamid, J. Mater. Chem., 2012, $22,6947$.

9 H. Namazi and M. Adeli, Biomaterials, 2005, 26, 1175;

I. Gitsov, Linear-Dendritic Block Copolymers. Synthesis and Characterization, "Advances in Dendritic Macromolecules”, ed. G. R. Newkome, Elsevier Science, Amsterdam2002, vol. 5, p. 45; D. Wilms, S.-E. Stiriba and H. Frey, Acc. Chem. Res., 2010, 43, 129; F. Hakimpoor, M. Ashiri, R. Kabiri, M. Bavadi and M. Adeli, Soft Matter, 2011, 7, 4062; A. Tavakoli, M. Vosoughi and M. Adeli, Nanomed.: Nanotechnol.,Biol.,Med., 2010, 6, 556.

10 M. Adeli, A. Kakanejadifard, M. Khani, F. Bani, R. Kabiri and M. Sadeghizad, J. Mater. Chem. B, 2014, 2, 3589.

11 R. Haag, H. Türk and S. Mecking, German Patent Application DE10211664A1, 2002; D. Steinhilber, S. Seiffert, J. A. Heyman, F. Paulus, D. A. Weitz and R. Haag, Biomaterials, 2011, 32, 1311.

12 Y. Oikawa, S. Lee, D. H. Kim, D. H. Kang, B.-S. Kim, K. Saito, S. Sasaki, Y. Oishi and Y. Shibasaki, Biomacromolecules, 2013, 14, 2171.

13 M. P. A. Lim, W. L. Lee, E. Widjaja and S. C. J. Loo, Biomater. Sci., 2013, 1, 486; R. R. Langer and J. P. Vacanti, Science, 1993, 260, 920; B. D. Ratner, A. S. Hoffman, F. J. Schoen and J. E. Lemons, Biomaterials Science: An Introduction to Material in Medicine, Academic Press, San Diego, 2000; M. R. Vijayakumar, M. S. Muthu and S. Singh, Expert Opin. Drug Delivery, 2013, 10, 529; Y. Deng, J. K. Saucier-Sawyer, C. J. Hoimes, J. Zhang, Y.-E. Seo, J. W. Anrejecsk and W. M. Saltzman, Biomaterials, 2014, 35, 6595.

14 X. Gao, X. Zhang, Z. Wu, X. Zhang, Z. Wang and C. Li, J. Controlled Release, 2009, 140, 141; S. Hecht, N. Vladimirov and J. M. J. Fréchet, J. Am. Chem. Soc., 2001, 123, 18; L. Elomaa, S. Teixeira, R. Hakala, H. Korhonen,
D. W. Grijpma and J. V. Seppälä, Acta Biomater., 2011, 7, 3850; C. Gottschalk, F. Wolf and H. Frey, Macromol. Chem. Phys., 2007, 208, 1657; A. M. Fischer, R. Thiermann, M. Maskos and H. Frey, Polymer, 2013, 54, 1993.

15 E. Fleige, K. Achazi, K. Schaletzki, T. Triemer and R. Haag, J. Controlled Release, 2014, 185, 99.

16 M. Schäfer-Korting, U. Bock, A. Gamer, A. Haberland, E. Haltner-Ukomadu, M. Kaca, H. Kamp, M. Kietzmann, H. C. Korting, H. U. Krächter, C. M. Lehr, M. Liebsch, A. Mehling, F. Netzlaff, F. Niedorf, M. K. Rübbelke, U. Schäfer, E. Schmidt, S. Schreiber, K. R. Schröder, H. Spielmann and A. Vuia, ATLA, Altern. Lab. Anim., 2006, 34, 283.

17 M. Schäfer-Korting, U. Bock, W. Diembeck, H. J. Düsing, A. Gamer, E. Haltner-Ukomadu, C. Hoffmann, M. Kaca, H. Kamp, S. Kersen, M. Kietzmann, H. C. Korting, H. U. Krächter, C. M. Lehr, M. Liebsch, A. Mehling, C. Müller-Goymann, F. Netzlaff, F. Niedorf, M. K. Rübbelke, U. Schäfer, E. Schmidt, S. Schreiber, H. Spielmann, A. Vuia and M. Weimer, ATLA, Altern. Lab. Anim., 2008, 36, 161.

18 S. L. Borgia, M. Regehly, R. Sivaramakrishnan, W. Mehnert, H. C. Korting, K. Danker, B. Röder, K. D. Kramer and M. Schäfer-Korting, J. Controlled Release, 2005, 110, 151.

19 J. Khandare, M. Calderon, N. M. Dagia and R. Haag, Chem. Soc. Rev., 2012, 41, 2824.

20 B. Trappmann, K. Ludwig, M. R. Radowski, A. Shukla, A. Mohr, H. Rehage, C. Böttcher and R. Haag, J. Am. Chem. Soc., 2010, 132, 11119.

21 R. Tyagi, S. Malhotra, A. F. Thünemann, A. Sedighi, M. Weber, A. Schäfer and R. Haag, J. Phys. Chem. C, 2013, 117, 12307.

22 E. Fleige, R. Tyagi and R. Haag, Nanocarriers, 2013, 1, 1. 